\title{
Children's Citrus Activity: Diaprepes Root Weevil'
}

\author{
Lauren M. Diepenbrock and Jamie D. Burrow²
}

Diaprepes weevils are a type of beetle that feeds on citrus trees and some decorative plants. These beetles came to Florida in the 1960s from the Caribbean. The larvae (babies/kids) feed underground on roots. Larvae are white and up to one inch long, and they have no legs. As larvae, their main job is to eat so they can develop into adults and leave their underground home.

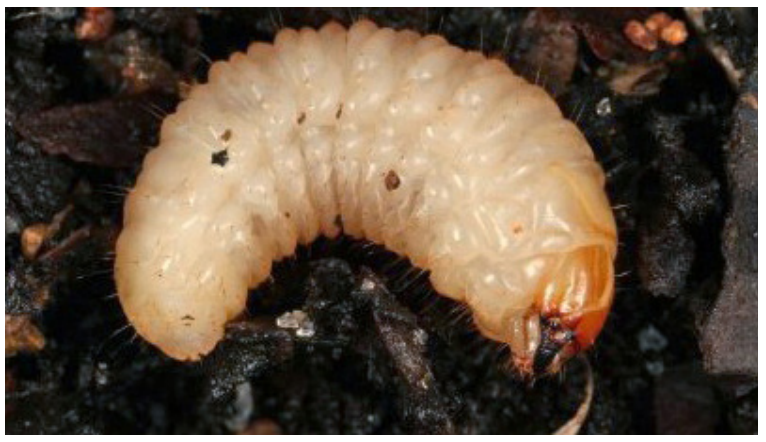

Figure 1. Diaprepes larva

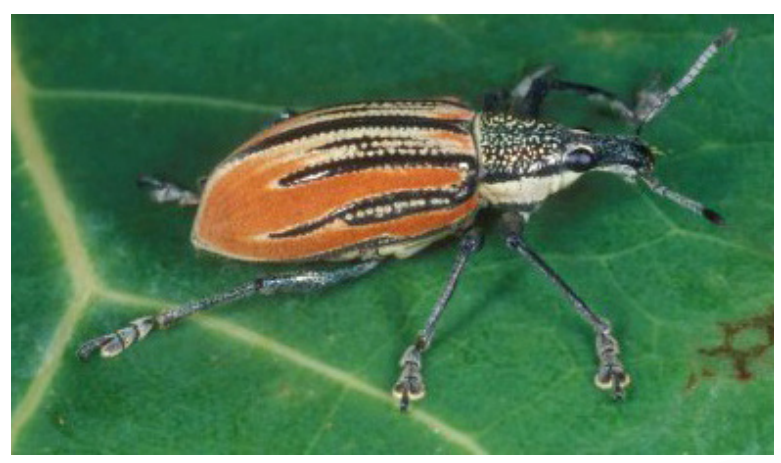

Figure 2. Diaprepes adult

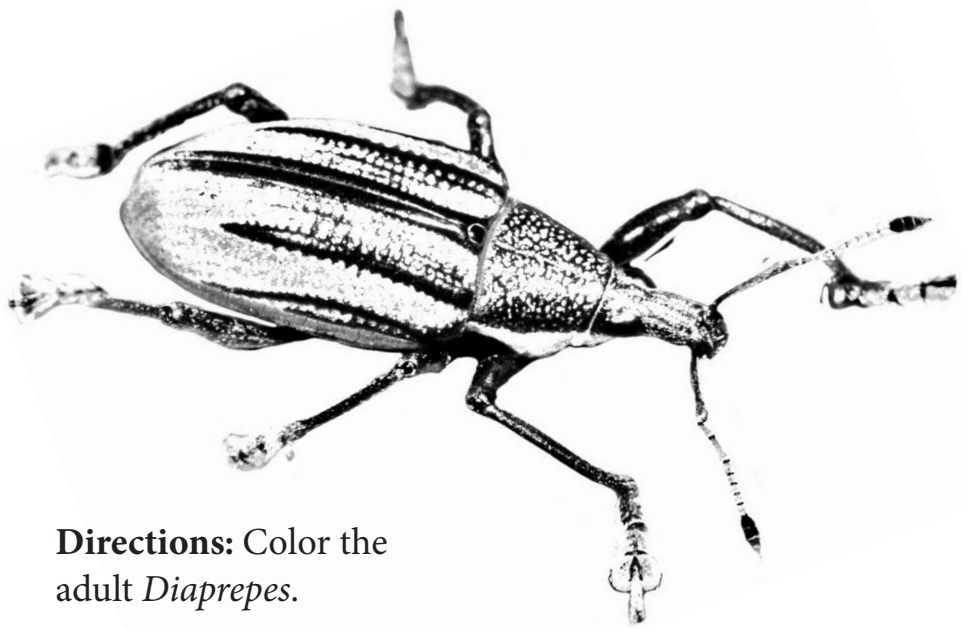

Adult diaprepes weevils feed on plant leaves. On its own, one beetle will only eat a small part of the leaf, but if a lot of adults feed on the same plant, they can cause a lot of damage. This damage can be expensive to prevent and control.

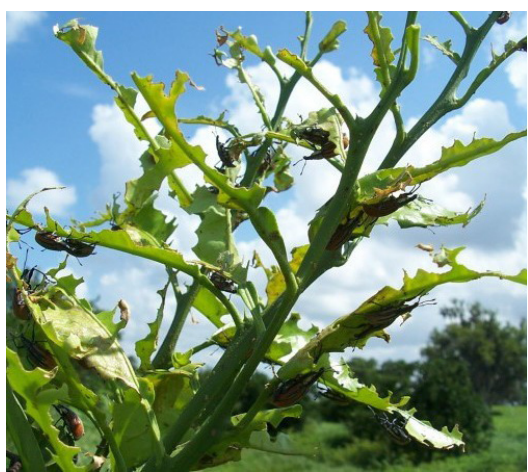

Figure 3. Feeding damage by adult larva Diaprepes.

Photo Credit: L. Buss, UF/IFAS; R. Stewart, FDACS; UF; Artwork Credit: Katherine M. Snyder, UF/IFAS CREC, Tonya Weeks, UF/IFAS CREC

1. This document is $4 \mathrm{H} 403$, one of a series of the 4-H Youth Development Program, UF/IFAS Extension. Original publication date July 2019. Visit the EDIS website at https://edis.ifas.ufl.edu for the currently supported version of this publication.

2. Lauren M. Diepenbrock, assistant professor, Entomology and Nematology Department; and Jamie D. Burrow, Extension program manager, UF/IFAS Citrus Research and Education Center, Lake Alfred, FL 33850. 
Directions: Help the larva exit the soil as an adult.

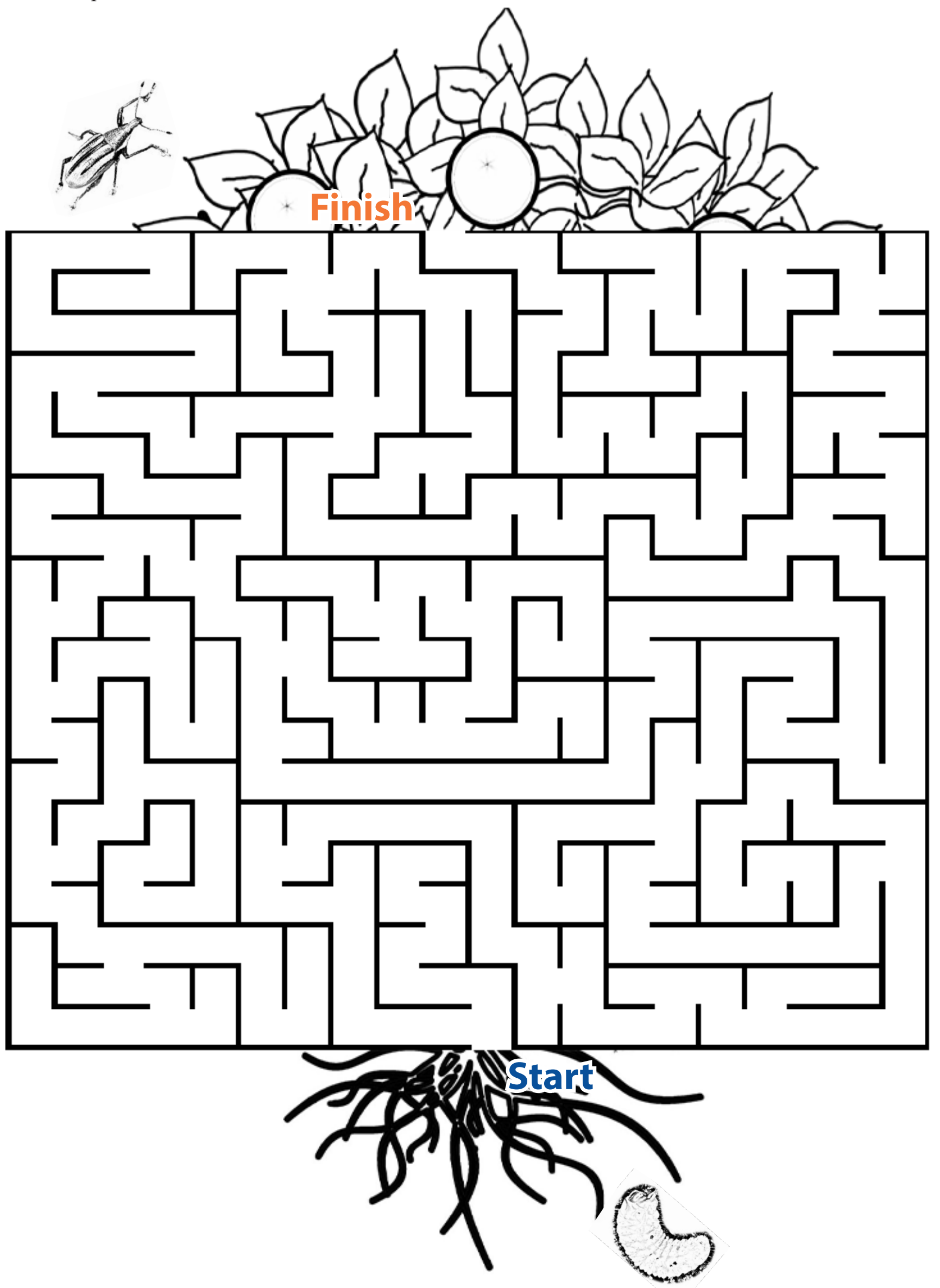

